\title{
Post-Christmas blues: A rare cause of cyanosis
}

\author{
Laurie Barron $\mathrm{MD}^{1}$, H Jay Biem MD FRCPC ${ }^{2}$ \\ ${ }^{1}$ Division of Orthopedics, and ${ }^{2}$ Division of General Internal Medicine, University of \\ Saskatchewan, Saskatoon, Saskatchewan
}

\begin{abstract}
L Barron, HJ Biem. Post-Christmas blues: A rare cause of cyanosis. Can Respir J 2001;8(1):39-40.

A patient was referred for urgent evaluation of cyanosis. Although she had symptoms and signs of an upper respiratory tract infection, she had a normal cardiorespiratory examination and normal transcutaneous oxygen saturation. Further evaluation revealed a benign cause for the cyanosis.
\end{abstract}

Key Words: Cyanosis; Dye

\section{Les « bleus » après Noël : cause rare de cyanose}

RÉSUMÉ : Une patiente a été vue en urgence pour cyanose. Même si elle présentait des signes et des symptômes d'une infection des voies respiratoires supérieures, l'examen cardiorespiratoire s'est avéré normal, de même que la mesure transcutanée de la saturation du sang en oxygène. Une évaluation plus poussée a révélé une cause bénigne de cyanose.

\section{CASE PRESENTATION}

Although cyanosis usually indicates serious medical illness, occasionally it can be benign. There is an extensive differential diagnosis for cyanosis, with some obscure causes peculiar to rural Saskatchewan. For example, a high concentration of nitrates in ground water in some areas may cause pigmentary cyanosis due to methemoglobinemia (1).

One week after Christmas, an 18-year-old woman was urgently referred from rural Saskatchewan with cyanosis. She complained of rhinorrhea, cough and feverishness. For the previous $24 \mathrm{~h}$, her family had observed her to appear blue. She had no shortness of breath.

In the emergency room, the patient was anxious and blue. Her vital signs were normal. She had rhinorrhea and nasal mucosal edema. Her lung fields were clear and cardiac examination was normal. The skin was warm to the touch and had normal capillary refill. There was a patchy, light-blue discoloration that was especially prominent over the extensor surfaces of the arms. The patient's transcutaneous oxygen saturation was normal. Cleansing the skin with an alcohol swab removed the blue discoloration (Figure 1). Further investigation of the patient's history revealed that

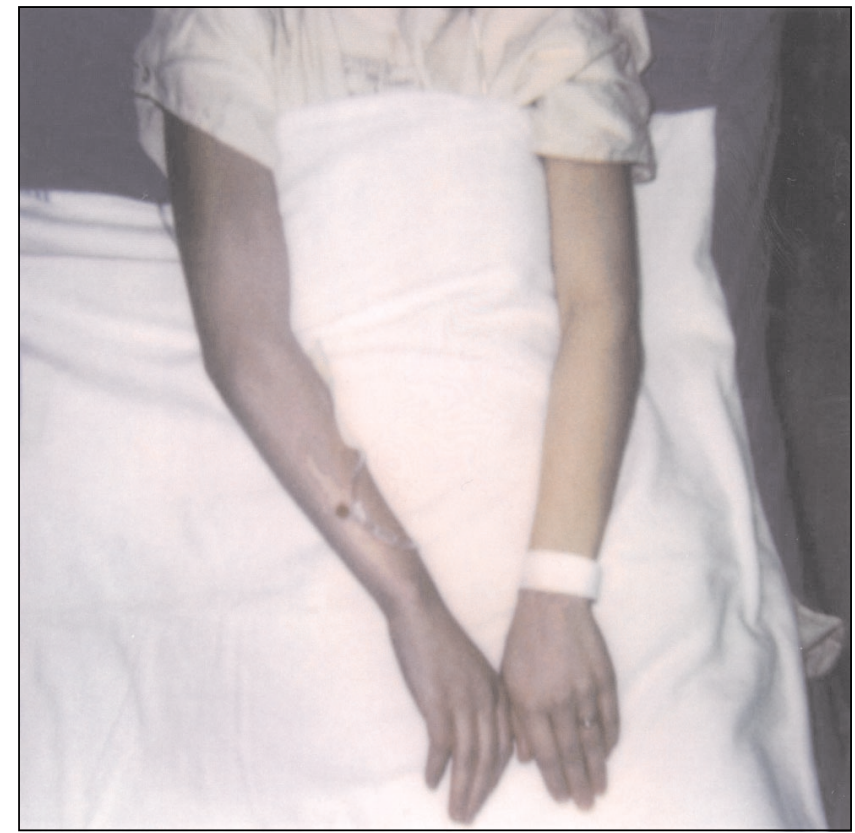

Figure 1) Photograph of patient after cleansing of the left arm. Note the difference in skin colour between the two upper extremities 
she had received a Christmas gift of new, blue-coloured bed linen.

\section{DISCUSSION}

'Cyanosis' related to exposure to chemical dyes has previously been described within a hospital nursery (2) and in a teenager in whom only the hands were affected (3). To our knowledge, the distribution of skin discoloration seen in our patient has not been reported before. We speculate that the staining of exposed skin may have been promoted by the diaphoresis accompanying the patient's upper respiratory tract infection. Physicians should consider skin staining from new cloth not only in the cyanotic patient with normal oxygen saturation, but also in the plethoric patient with normal hemoglobin and in the jaundiced patient with normal bilirubin.

\section{REFERENCES}

1. Douthwaite AH, ed. French's Index of Differential Diagnosis, 7th edn. Bristol: John Wright \& Sons Limited, 1954:195-204.

2. Opala R. Baby blues. Med J Aust 1997;167:288. (Lett)

3. Kapsar PJ Jr. Cyanotic hands syndrome. J Emerg Nurs 1984;10:279. (Lett) 


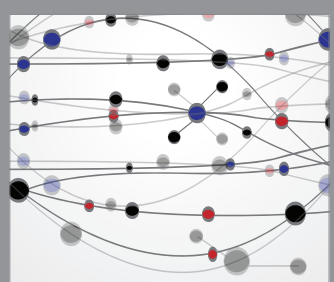

The Scientific World Journal
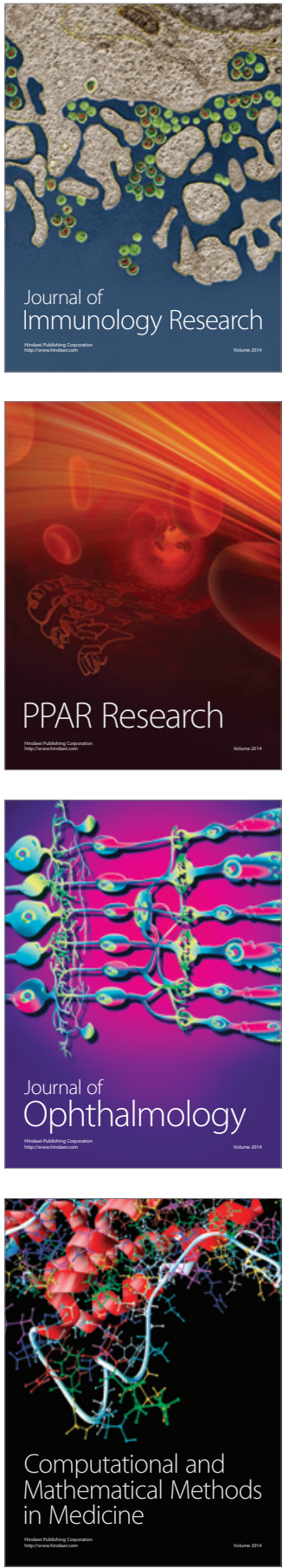

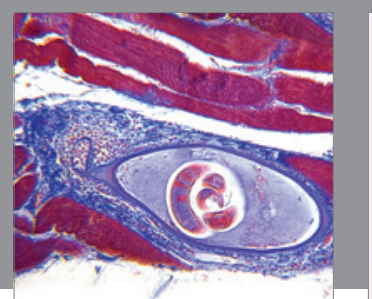

Gastroenterology Research and Practice

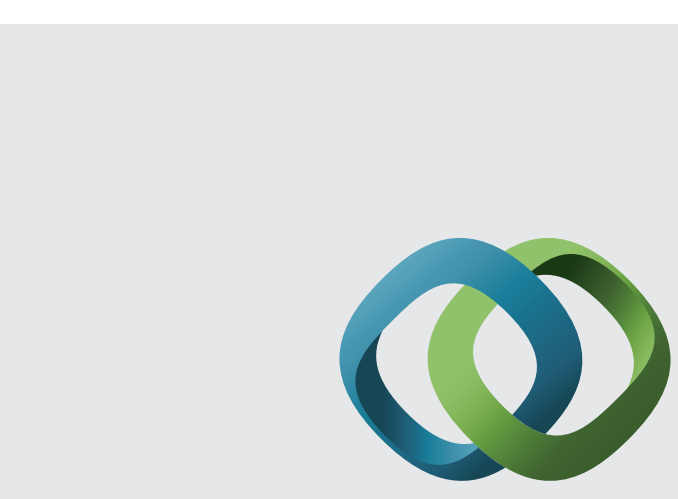

\section{Hindawi}

Submit your manuscripts at

http://www.hindawi.com
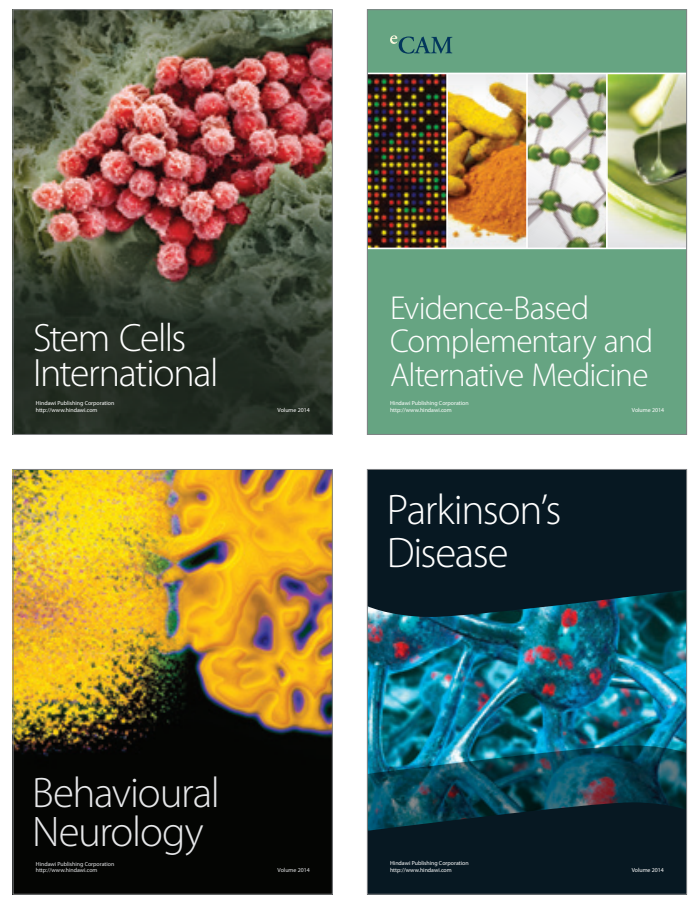
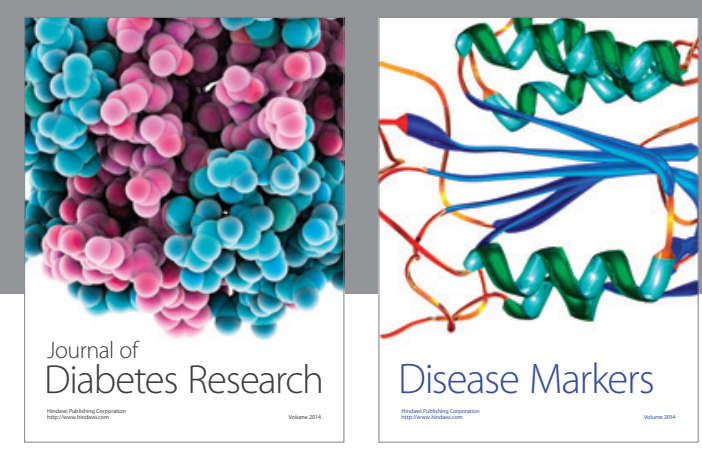

Disease Markers
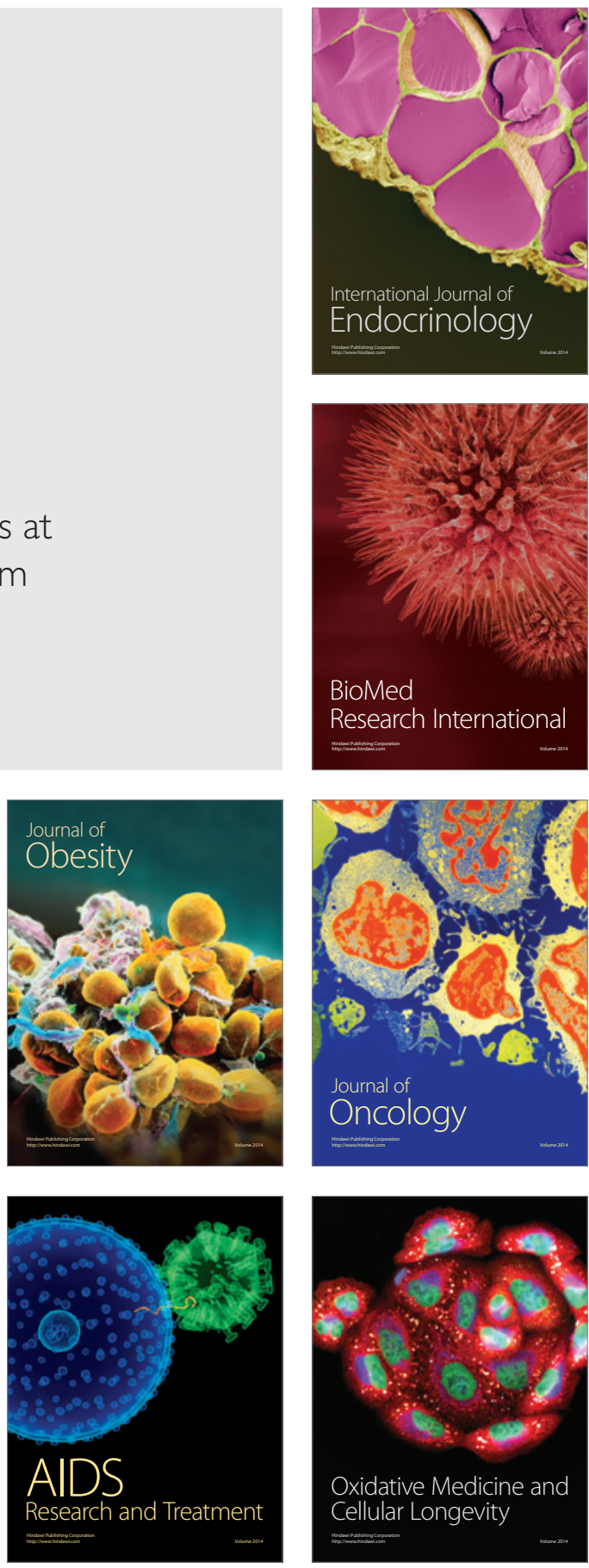